\title{
Article
}

\section{LEDGF/p75 Is Required for an Efficient DNA Damage Response}

\author{
Victoria Liedtke ${ }^{1} \mathbb{D}$, Christian Schröder ${ }^{1}$, Dirk Roggenbuck ${ }^{1,2}{ }^{10}$, Romano Weiss ${ }^{1}$, Ralf Stohwasser ${ }^{1,2}$, \\ Peter Schierack ${ }^{1,2}$, Stefan Rödiger $1,2,+(1)$ and Lysann Schenk ${ }^{1, *, \dagger}$
}

1 Faculty of Natural Sciences, Brandenburg University of Technology Cottbus-Senftenberg, 01968 Senftenberg, Germany; Victoria.Liedtke@b-tu.de (V.L.); Ch.Schroeder@b-tu.de (C.S.); Dirk.Roggenbuck@b-tu.de (D.R.); Romano.Weiss@b-tu.de (R.W.); Ralf.Stohwasser@b-tu.de (R.S.); Peter.Schierack@b-tu.de (P.S.); Stefan.Roediger@b-tu.de (S.R.)

2 Faculty of Health Sciences Brandenburg, Brandenburg University of Technology Cottbus-Senftenberg, 01968 Senftenberg, Germany

* Correspondence: Lysann.Schenk@b-tu.de

+ Shared senior authorship.

check for updates

Citation: Liedtke, V.; Schröder, C.; Roggenbuck, D.; Weiss, R.; Stohwasser, R.; Schierack, P.; Rödiger, S.; Schenk, L. LEDGF/p75 Is Required for an Efficient DNA Damage Response. Int. J. Mol. Sci. 2021, 22, 5866. https://doi.org/ $10.3390 /$ ijms 22115866

Academic Editors: Hans J. Lipps and Jan Postberg

Received: 18 April 2021

Accepted: 27 May 2021

Published: 30 May 2021

Publisher's Note: MDPI stays neutral with regard to jurisdictional claims in published maps and institutional affiliations.

Copyright: (c) 2021 by the authors. Licensee MDPI, Basel, Switzerland. This article is an open access article distributed under the terms and conditions of the Creative Commons Attribution (CC BY) license (https:// creativecommons.org/licenses/by/ $4.0 /)$.

\begin{abstract}
Lens epithelium-derived growth factor splice variant of $75 \mathrm{kDa}$ (LEDGF/p75) plays an important role in cancer, but its DNA-damage repair (DDR)-related implications are still not completely understood. Different LEDGF model cell lines were generated: a complete knock-out of LEDGF (KO) and re-expression of LEDGF/p75 or LEDGF/p52 using CRISPR/Cas9 technology. Their proliferation and migration capacity as well as their chemosensitivity were determined, which was followed by investigation of the DDR signaling pathways by Western blot and immunofluorescence. LEDGF-deficient cells exhibited a decreased proliferation and migration as well as an increased sensitivity toward etoposide. Moreover, LEDGF-depleted cells showed a significant reduction in the recruitment of downstream DDR-related proteins such as replication protein A $32 \mathrm{kDa}$ subunit (RPA32) after exposure to etoposide. The re-expression of LEDGF/p75 rescued all knock-out effects. Surprisingly, untreated LEDGF KO cells showed an increased amount of DNA fragmentation combined with an increased formation of $\gamma \mathrm{H} 2 \mathrm{AX}$ and BRCA1. In contrast, the protein levels of ubiquitin-conjugating enzyme UBC13 and nuclear proteasome activator PA28 $\gamma$ were substantially reduced upon LEDGF KO. This study provides for the first time an insight that LEDGF is not only involved in the recruitment of CtIP but has also an effect on the ubiquitin-dependent regulation of DDR signaling molecules and highlights the role of LEDGF/p75 in homology-directed DNA repair.
\end{abstract}

Keywords: LEDGF; CRISPR/Cas9; DNA damage signaling; $\gamma \mathrm{H} 2 \mathrm{AX}$; ubiquitination

\section{Introduction}

Dense fine speckled autoantigen of $70 \mathrm{kDa}$ (DFS70) also known as lens epitheliumderived growth factor (LEDGF), PSIP1 (PC4 and SFRS1 interacting protein 1), or transcriptional co-activator p75 is considered a ubiquitous nuclear transcription co-activator [1]. It is linked to various diseases such as cancer and acquired immunodeficiency syndrome (AIDS), and diverse inflammatory conditions have been described as well [2,3]. LEDGF/p75 shows anti-apoptotic activity by promoting the repair of DNA double-strand breaks (DSBs) via the homology-directed repair pathway (HDR) [4], and its overexpression in different cancer cell lines and solid tumors has been linked to tumor progression, aggressiveness, and chemoresistance [5]. In contrast, the shorter splice variant LEDGF/p52 has been proposed to play a pro-apoptotic role and appears to be involved in RNA-splicing [6,7]. LEDGF/p75 is a multi-functional, chromatin-binding protein upregulated in different solid cancer and cancer cell lines [1], promoting the activation of pathways involved in proliferation, cell survival, and DNA repair [4,8]. The SUMOylation of LEDGF/p75 [9] by sumo-specific protease- 1 regulates its binding in promoter regions of stress-related proteins. This protects cells from stress-induced necrosis and enhances the activation of the Akt/ERK signaling 
pathway, resulting in an increased tumor aggressiveness [1,10]. In addition to the upregulation in response to oxidative stress, the mechanism by which LEDGF/p75 protects cancer cells from stress-induced necrosis is not clarified. However, LEDGF/p75 can activate the expression of cancer-related genes e.g., vascular endothelial growth factor C (VEGF-C) as a transcriptional coactivator by protein-protein interaction $[4,11,12]$. It has been shown in prostate cancer cells that LEDGF/p75 facilitates chemotherapy resistance by counteracting caspase-independent apoptosis [12]. DNA damage response (DDR) is a finely tuned signaling network required to repair potentially lethal DNA double-strand breaks (DSBs) and other DNA lesions. LEDGF/p75 interacting with this network supports rapid repair of DSBs. Thus, LEDGF/p75 recruits the histone acetyltransferase KAT5 to the chromatin, which acetylates histone 4 (H4) at lysine K16 [13]. This acts as a switch between HDR and non-homologous end-joining (NHEJ). Upon H4 acetylation, the BRCA1-BARD1 complex can bind to DNA, supporting HDR. Without H4 acetylation, BRCA1-BARD1 binding is inhibited by 53BP1, which in turn triggers NHEJ [14]. Interestingly, BRCA1 acts upstream (DNA damage sensor) and downstream (participation in various DNA repair complexes) of LEDGF [15]. The termination of DDR is accomplished by the ubiquitination of key regulators such as $\gamma \mathrm{H} 2 \mathrm{AX}$ or BRCA1 [16,17]. The LEDGF-dependent BRCA1-BARD1 complex is a member of the E3-ubiquitin protein ligase family [18]. It is involved in ubiquitin-dependent regulation and signal termination of $\gamma \mathrm{H} 2 \mathrm{AX}$ [19]. Ubiquitination triggers degradation by the ubiquitin-proteasome system (UPS) and ubiquitin-independent proteasome pathway (UIPP) [20].

We have created LEDGF knockout (KO), EGFP-LEDGF/p75 re-expressing (LEDGF/p75 $\mathrm{o} / \mathrm{e}$ ), and mEmarald_LEDGF/p52 re-expressing (LEDGF/p52 o/e) cells using CRISPR/Cas9 technology to analyze the expression of various DDR proteins. Our work showed for the first time the participation of LEDGF/p75 in the ubiquitin-dependent regulation of DDR signaling molecules.

\section{Results}

\subsection{CRISPR/Cas9-Generated LEDGF Cell Models}

For complete knock-out of the LEDGF gene PSIP1, the sgRNA was designed within exon 1 of the PSIP1 gene to target all splice variants (Figure 1). Then, HEp-2 WT and U2OS WT cells were transfected with non-viral px458_DFS70_E1 vector co-expressing EGFP as a marker and Cas9 enzyme and enriched via EGFP-directed FACS sorting (Figure S1A) following single cell out-growth. The LEDGF KO HEp-2 clones were verified at a protein and genomic level (Figures 1E and S1C,D). Potential genomic off-target loci were checked by sequencing and exhibited all unmodified loci (Figure S1E). The reconstitution of LEDGF in LEDGF KO was realized by the integration of either EGFP-LEDGF/p75 expression cassette (Figure 1B) or mEmarald_LEDGF/p52 expression cassette at the human safe harbor locus (AAVS1) (Figures 1E,F and S1B). EGFP-LEDGF/p75 and mEmarald_LEDGF/p52 incorporation and constitutive expression was confirmed by detecting the fluorescent LEDGF fusion protein (Figure 1C). Both expressed splice variants showed the typical nuclear localization. Additionally, C-terminal LEDGF antibody was used to detect the wild-type LEDGF and EGFP-LEDGF/p75 to show the typical dense fine speckled nuclear staining pattern (Figure 1D). Note, mEmarald_LEDGF/p52 cannot be detected with this antibody, as p52 is missing the C-terminus. 
A.

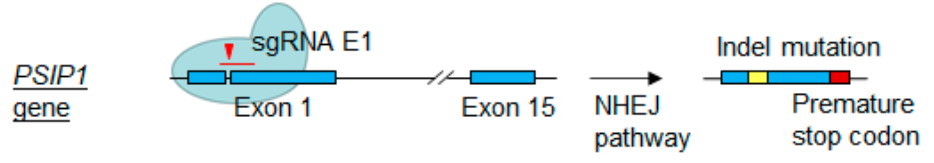

B.

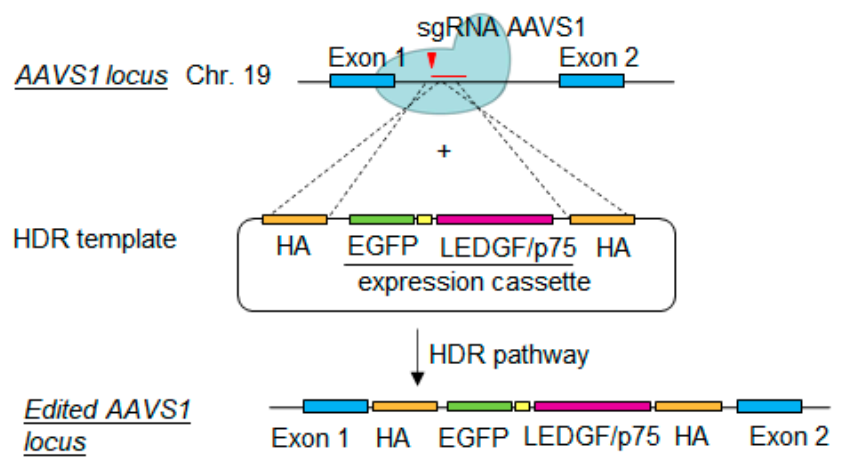

c.
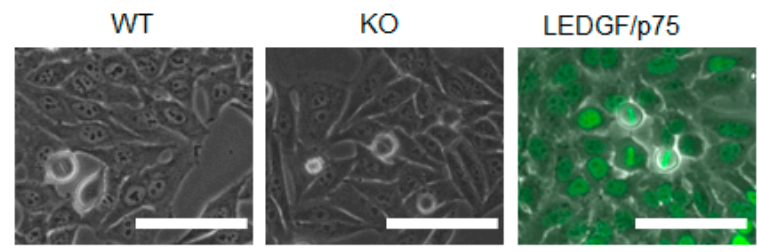

LEDGF/p52

D.
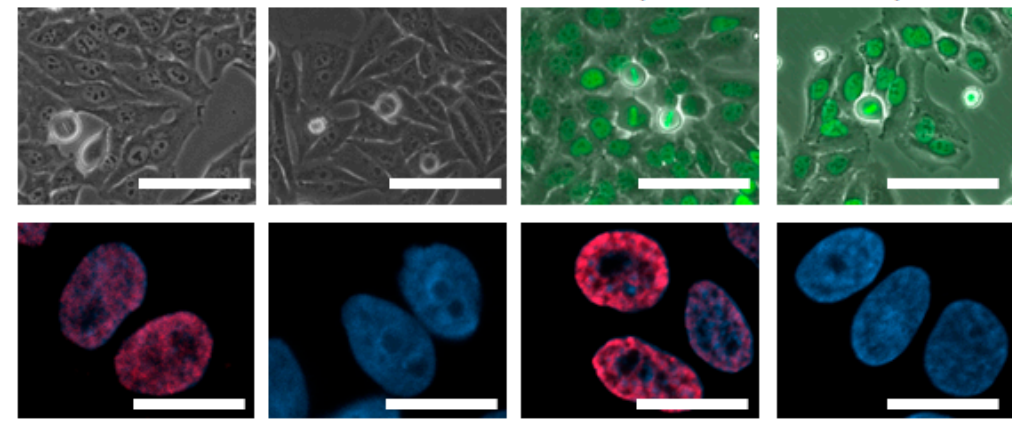

E.

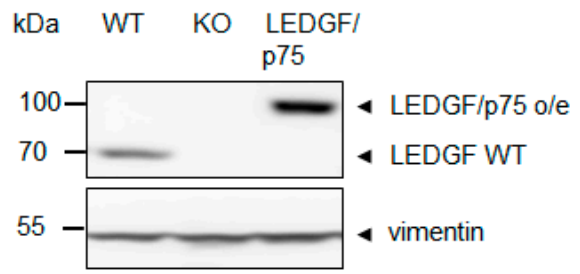

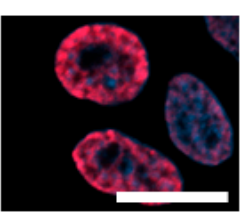

F.
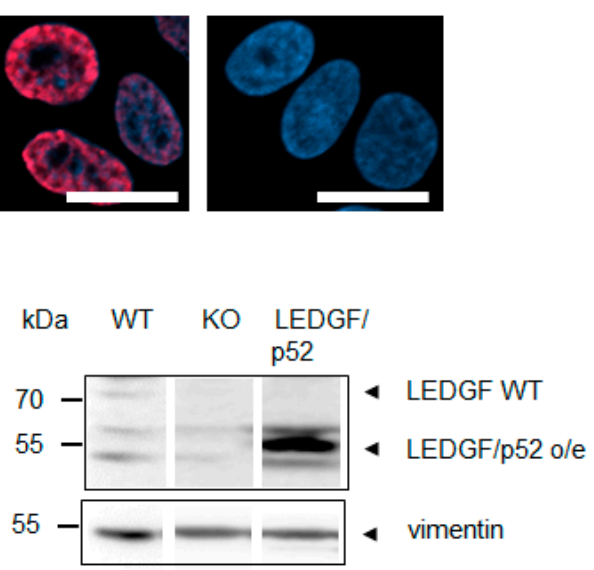

Figure 1. Verification of CRISPR/Cas9-mediated LEDGF knockout and LEDGF re-expression in HEp-2 cells. (A) Specific sgRNA for Exon 1 of LEDGF-coding gene PSIP1 was designed to knockout (KO) LEDGF. The Cas9/sgRNA E1 complex induces double-strand breaks, which can be repaired by the cells through non-homologous end joining (NHEJ); however, NHEJ is error-prone, leading to indel mutations, which can cause premature stop codons. (B) LEDGF/p75 and LEDGF/p52 re-expressing cells were created by introducing a DNA DSB at a genomic safe-harbor locus (AAVS1) using an AAVS1-specific sgRNA. After the induction of a DSB, homology-directed repair (HDR) mediates the integration of the donor template containing the EGFP-LEDGF/p75 or a mEmarald_LEDGF/p52 expression cassette at the AAVS1 locus. Generated LEDGF knockout and re-expressing cells were verified by (C) fluorescence analysis with an excitation wavelength of $488 \mathrm{~nm}$ (scale bar $=100 \mu \mathrm{m}),(\mathrm{D})$ indirect immunofluorescence (IF). Anti C-LEDGF antibody appear red due to conjugation to $\alpha$-rabbitIgG-Atto 647 secondary antibody, nuclei appear blue due to DAPI incorporation (scale bar $=20 \mu \mathrm{m}$ ). (E) Immunoblot using antibodies against C-terminal LEDGF and vimentin as loading control. (F) Immunoblot with antibodies against $\mathrm{N}$-terminal LEDGF and vimentin as loading control.

\subsection{Depletion of LEDGF Decreases Cellular Migration}

LEDGF has been previously shown to affect cell migration. Therefore, the cell migration of HEp-2 and U2OS cells was checked. Indeed, the migratory capacity was significantly reduced upon LEDGF knockout in HEp-2 and U2OS cells (Figure 2). LEDGF/p52 
re-expression failed to restore the migration capacity of the HEp-2 WT (Figure 2A,C). In contrast, LEDGF/p75 re-expression (WT level) reversed the inhibiting effect, and the cell migration ability was further improved with higher LEDGF/p75 levels (oe) in comparison to the unmodified WT cells (Figures 2C and S4). Additionally, EGFP-LEDGF/p75 o/e cells showed a changed morphology toward an elongated, fibroblast-like phenotype in combination (Figure 2D) with an increased expression of the cytoskeleton subunit $\alpha$-tubulin (Figure 2B). Morphological analysis revealed that LEDGF/p75 o/e cells exhibited a significantly increased eccentricity and a significantly decreased round shape by $50 \%(p<0.05$, Figure 2D). However, LEDGF KO cells showed a reduced expression of $\alpha$-tubulin but no change in morphology (Figure 2B).

\subsection{LEDGF Depletion Sensitizes Cancer Cells toward Etoposide}

Already as a result of LEDGF KO, cells showed a significant decrease in cell proliferation in comparison to the WT cells, while no changes in the cell cycle were detectable (Figures 3A and S2). The re-expression of LEDGF/p75 completely rescued the proliferation rate, implicating that the $\mathrm{p} 75$ splice variant is the most relevant for cell growth. For the proliferation analysis, the cell lines were used within 10 passages. During this time, no changes in growth behavior could be detected. As shown in Figure 3A, the lower proliferation rate was reflected by a prolonged doubling time (WT $21 \mathrm{~h}$ and KO $26.5 \mathrm{~h}$ ). In addition, LEDGF KO cells were passaged 30 times without showing any visible increased apoptotic phenotype nor complete death. Upon etoposide exposure, LEDGF KO cells showed a significantly reduced cell survival compared to the WT (Figure 3B). Furthermore, the recovery rate after etoposide withdrawal was lower in LEDGF KO cells, as confirmed by $\mathrm{ED}_{50}$ determinations suggesting that LEDGF plays a critical role in chemosensitivity toward etoposide (Figure $3 \mathrm{C}$ ). We were able to compensate the reduced survival of LEDGF KO cells $\left(E_{50}=0.123 \pm 0.01\right.$ ) by re-expressing LEDGF (EGFP-LEDGF $/ \mathrm{p} 75 \mathrm{o} / \mathrm{e}$, $\mathrm{ED}_{50}=0.4 \pm 0.04$ ), which resulted in an etoposide resistance equal to unmodified WT-cells $\left(\mathrm{ED}_{50}=0.317 \pm 0.03\right)$ (Figure 3B,C).

\subsection{LEDGF Depletion Impairs DNA Damage Response via Homology-Directed Repair}

LEDGF has been previously implicated to play a crucial role in HDR-mediated damage response involving CtIP-BRCA1-RPA32 signaling [21]. Therefore, we investigated RPA32 foci formation combined with $\mathrm{yH} 2 \mathrm{AX}$ foci and DNA fragmentation to detect active HR.

LEDGF knockout in HEp-2 cells caused a significant increase in sensitivity toward etoposide shown by a higher killing rate (Figure 3B). This phenotype was underlined by phosphorylation of $\mathrm{H} 2 \mathrm{AX}(\gamma \mathrm{H} 2 \mathrm{AX}$, Figure 4$)$ and an increased level of DNA fragmentation (Figure 4B) indicating etoposide-induced DSBs; however, it was similar to wild-type HEp-2 cells. In contrast, the phosphorylation of RPA32 (pRPA upper band in Figure 4A after etoposide treatment) was almost completely abolished in LEDGF KO cells, while wild-type cells showed an elevated phosphorylation level. This was also reflected in significantly reduced RPA32 foci formation (Figure 4D,E) after etoposide treatment in LEDGF KO cells, indicating an inhibition of CtIP-BRCA1-mediated homology-directed repair. The re-expression of LEDGF/p75 was able to rescue the RPA32 foci formation (Figure 4D,E). 
A.
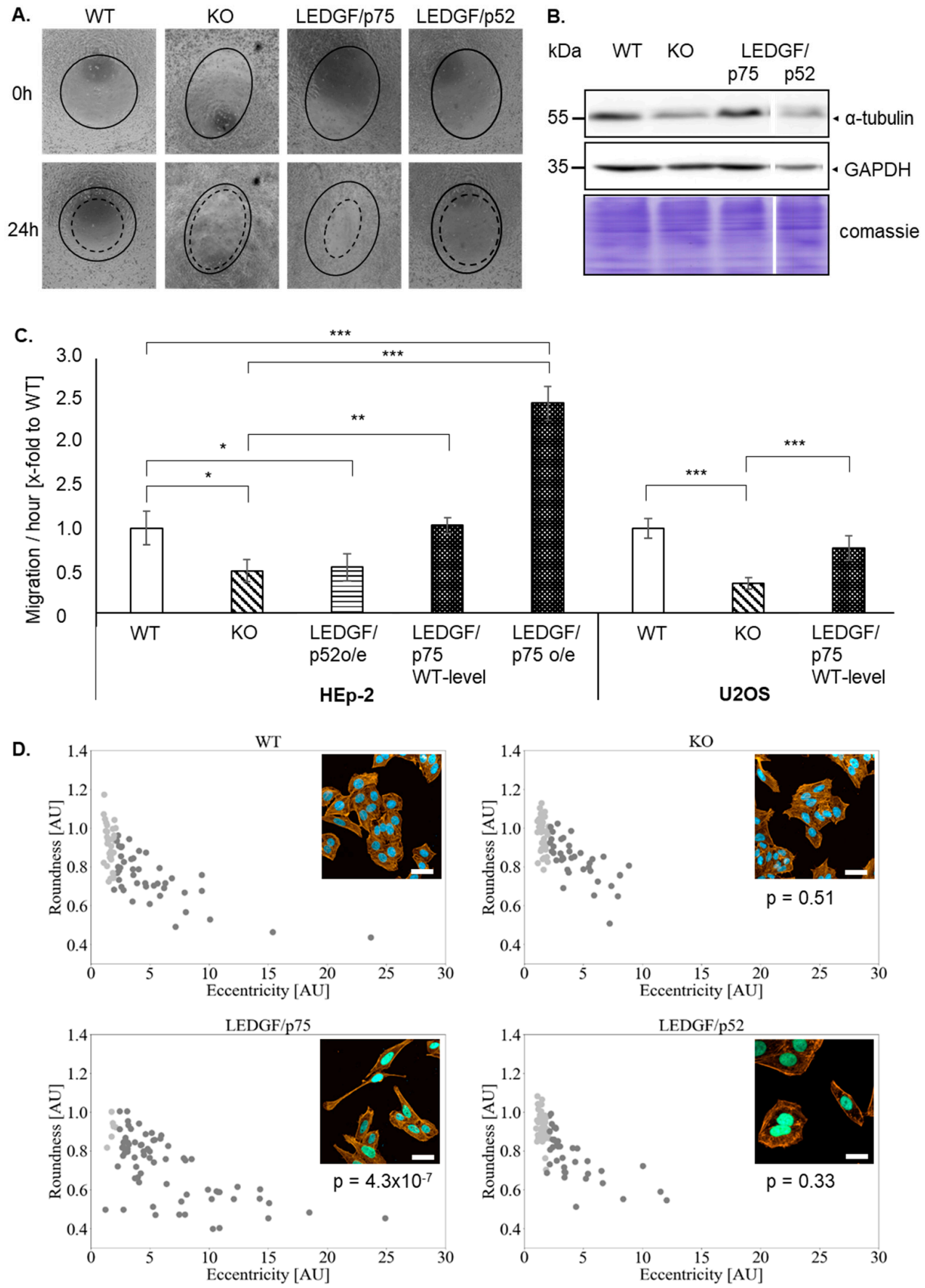

Figure 2. LEDGF influences cell migration and morphology. (A) Representative phase contrast image of HEp-2 WT, LEDGF K.O., LEDGF/p75, and LEDGF/p52 overexpressing cells, $0 \mathrm{~h}$ (black line) and $24 \mathrm{~h}$ (dashed line) after creating a circular scratch in a cell monolayer. Prior to the scratch, cells were incubated in $10 \mu \mathrm{g} / \mathrm{mL}$ mitomycin $\mathrm{C}$ to inhibit cell proliferation. (B) Immunoblot shows the level of $\alpha$-tubulin in untreated cells. As loading control, gel was stained with Coomassie brilliant blue to visualize total protein amount (10 $\mu \mathrm{g} /$ lane), and GAPDH antibody was used. (C) The wound-healing capacity of the indicated HEp-2 and U2OS cell clones were analyzed using an ImageJ plugin MRI wound-healing tool after $24 \mathrm{~h}$ of the scratch induction and plotted as area/hour. (D) Representative confocal images of HEp-2 WT, LEDGF KO, LEDGF/p75, and LEDGF/p52 overexpressing cells were taken after incubation with Phalloidin-AlexaFluor555 (yellow). Chromatin appears blue due to DAPI incorporation, nuclei of LEDGF/p75 overexpressing cells appear green due to EGFP-tag of LEDGF/p75, scale bar $=20 \mu \mathrm{m}$. The images were used to perform a DBSCAN clustering correlating cell roundness and eccentricity in HEp-2 WT, LEDGF K.O., LEDGF/p75 and LEDGF/p52 overexpressing cells ( $n=672$, whereby only 75 cells are shown per condition). Cells with fibroblast-like morphology are shown in dark gray and cells with roundish morphology are shown in light gray. ${ }^{*} p<0.05,{ }^{* *} p<0.01,{ }^{* * *} p<0.001$. 
A.

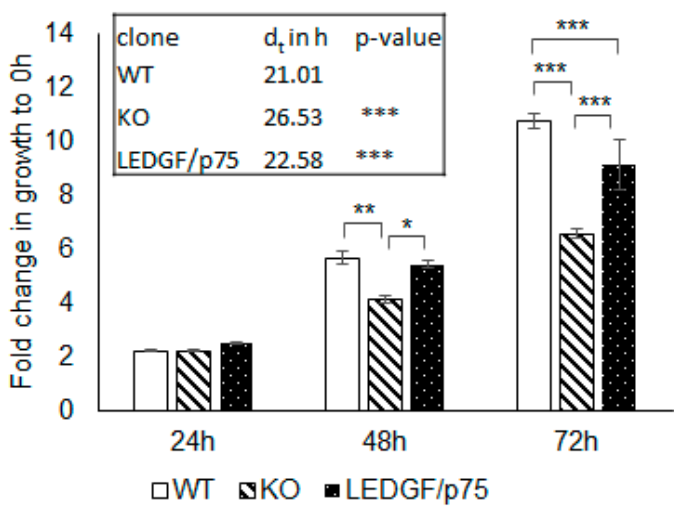

B.

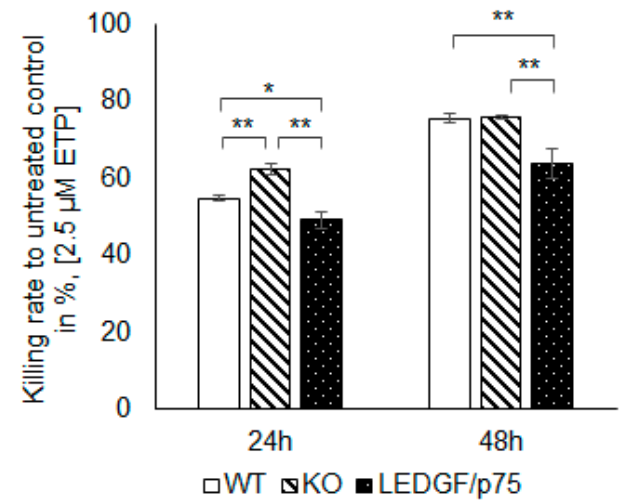

c.
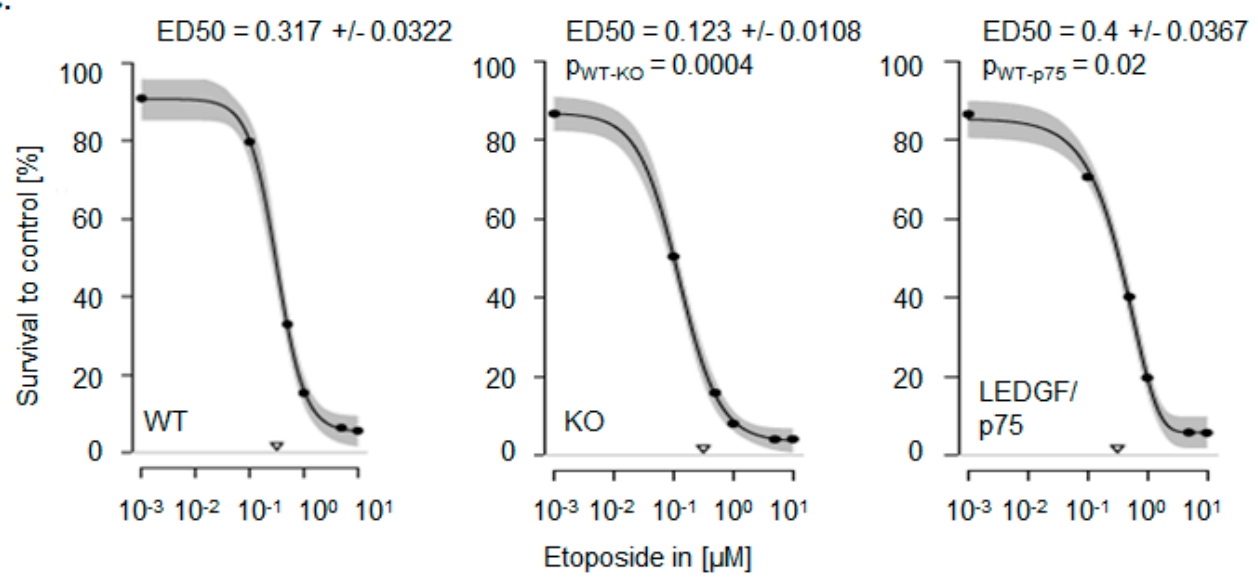

Figure 3. LEDGF affects cell proliferation and chemoresistance. (A) Proliferation of non-treated HEp-2 WT (passage 15-23), LEDGF KO (passage 6-13), and LEDGF/p75 re-expressing (passage 5-12) was determined for $0 \mathrm{~h}, 24 \mathrm{~h}, 48 \mathrm{~h}$ $(\mathrm{pWT}-\mathrm{KO}=0.006, \mathrm{pKO}-\mathrm{p} 75=0.015, \mathrm{pp} 75-\mathrm{WT}=0.705)$, and $72 \mathrm{~h}\left(\mathrm{pWT}-\mathrm{KO}=3 \times 10^{-6}, \mathrm{pKO}-\mathrm{p} 75=7 \times 10^{-5}, \mathrm{pp} 75-\mathrm{WT}=0.03\right)$ by SRB assay. Doubling time (dt) was determined for the HEp-2 WT, LEDGF KO, and LEDGF/p75 re-expressing cell line $\left(\mathrm{pWT}-\mathrm{KO}=3.4 \times 10^{-5}, \mathrm{pp} 75-\mathrm{KO}=2.6 \times 10^{-4}\right) .(\mathbf{B})$ After $24 \mathrm{~h}$ growth, indicated cell lines were treated with $1.25 \mu \mathrm{M}$ etoposide for $24 \mathrm{~h}$ (pWT-KO = 0.010, pKO-p75 = 0.0004, pp75-WT = 0.022) and $48 \mathrm{~h}(\mathrm{pWT}-\mathrm{KO}=0.044, \mathrm{pKO}-\mathrm{p} 75=0.0002$, pp75-WT $=0.0021$ ), and the survival rate was determined in comparison to the untreated control. (C) Determination of ED50 value of HEp-2 WT, LEDGF KO, and LEDGF/p75 o/e cells after 48 h etoposide treatment, followed by 3 days of recovery. Dose-response curves were fitted (95\% confidence interval) with multiparametric functions (EXD3: Three-parameter exponential decay model; LL4: Four-parameter log-logistic model, pWT-KO $=0.0004$, pWT-p75 $=0.02$ ). The triangles on the $x$-axis represent the dose of etoposide needed to reach $\mathrm{ED}_{50} \cdot{ }^{*} p<0.05,{ }^{* *} p<0.01,{ }^{* * *} p<0.001$.

\subsection{LEDGF Depletion Results in Dysfunctional DNA Damage Response}

Interestingly, $\gamma \mathrm{H} 2 \mathrm{AX}$ was already increased without DSB-inducing agents in LEDGF $\mathrm{KO}$ cells (Figure 4A). Additionally, pulse-field electrophoresis revealed a significantly increased amount of DNA fragmentation in untreated LEDGF KO cells (Figure 4B,C). Surprisingly, LEDGF KO cells exhibited not only a significantly higher number of persistent $\gamma \mathrm{H} 2 \mathrm{AX}$ foci (Figures 5 and S3C) but also a significantly increased foci formation (foci/nucleus are shown in Figure S7) of the DNA damage response molecule BRCA1 (Figures 5A,B and S3B). Both elevated foci formations were reversed by the re-expression of EGFP-LEDGF/p75 (Figures 5A-D and S3). 
A.

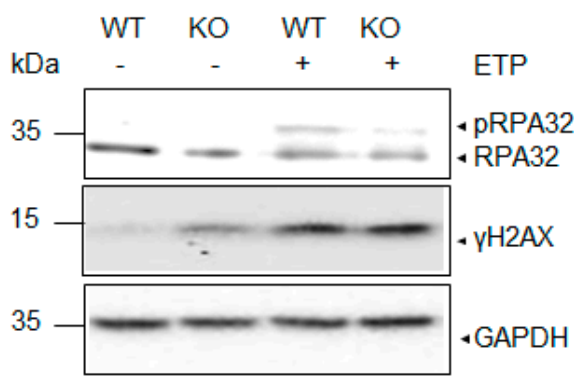

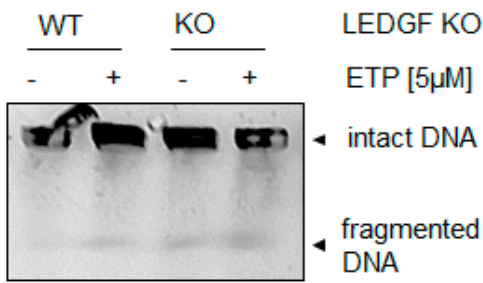

D.

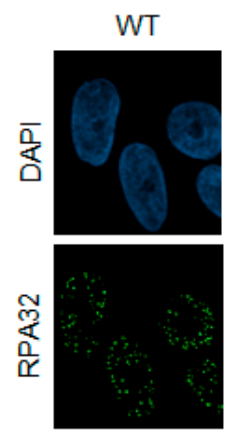

LEDGF/ p75 o/e

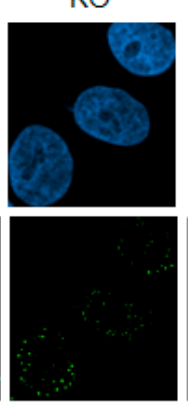

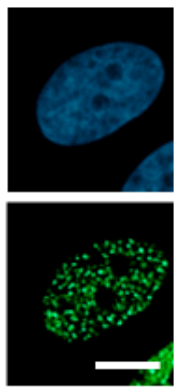

c.

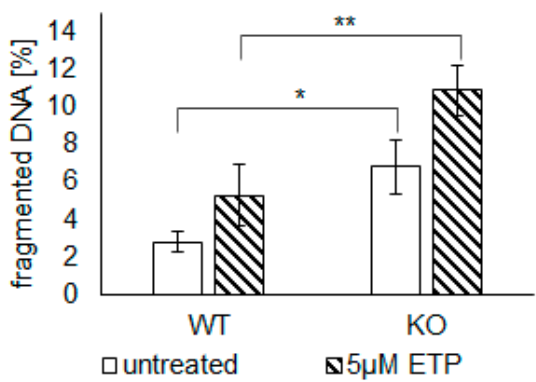

E.

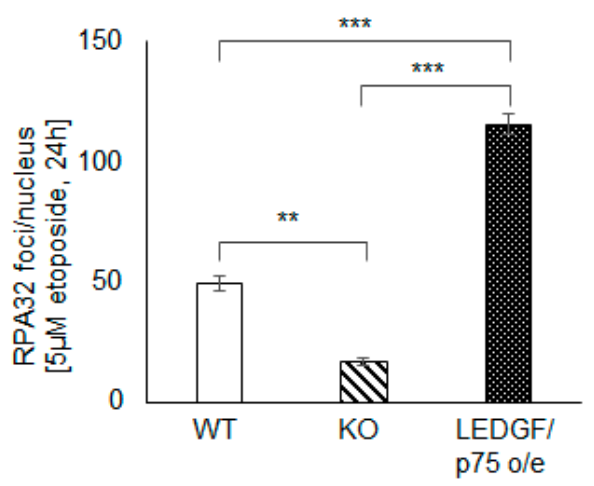

Figure 4. LEDGF necessary for CtIP-BRCA1-mediated homology-directed repair. (A) Immunoblots show levels of RPA32 (upper band phosphorylated RPA, pRPA), $\gamma \mathrm{H} 2 \mathrm{AX}$, and GAPDH in untreated cells and cells after treatment with $5 \mu \mathrm{M}$ etoposide for $6 \mathrm{~h}$. (B) Pulsed field gel electrophoresis (PFGE) with $5 \times 10^{5}$ cells/insert of HEp-2 WT and LEDGF KO cells.

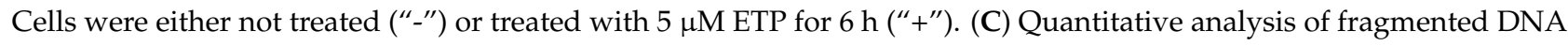
in HEp-2 WT and LEDGF KO cells as shown exemplary in Figure 4C. $(n=3)$. (D) Representative images of RPA32 foci are shown in indicated cells treated with $5 \mu \mathrm{M}$ etoposide for $16 \mathrm{~h}$. Cells were fixed with $2 \%$ formaldehyde and incubated anti-RPA32 (Santa Cruz Biotechnology, green). Chromatin appears blue due to DAPI incorporation. Scale bar: $10 \mu \mathrm{m}$. (E) Analysis of RPA32 foci (at least 100 cells were counted) was performed using NucDetect software, $n=3$. ${ }^{*} p<0.05$, ** $p<0.01, * * *<<0.001$.

Despite the high "basal" $\gamma \mathrm{H} 2 \mathrm{AX}$ foci in LEDGF KO cells, indicating permanent DNA damage, the cells were able to be maintained over 20-30 passages without dying even though at a significantly slower growth rate (Figure $3 \mathrm{~A}$ and data not shown). Therefore, we were interested in whether the sustained $\gamma \mathrm{H} 2 \mathrm{AX}$ foci are related to a dysregulated degradation of the histone. It has been previously stated that ubiquitination plays an important role in the regulation of DNA damage response signaling. For the $\gamma \mathrm{H} 2 \mathrm{AX}$ molecule, K63-linked ubiquitination by UBC13 is important in order to activate the BRCA1A complex, which coordinates the release of $\gamma \mathrm{H} 2 \mathrm{AX}$ followed by subsequent degradation of the proteasome (as illustrated in Figure 5G [16]). This happens downstream of LEDGFinduced CtIP-BRCA1-RPA32 DNA damage signaling.

Here, we show for the first time that LEDGF depletion had a significantly reducing effect on the protein expression levels of UBC13 as well as PA28 $\gamma$ also known as REGy (Figure 5E in Hep-2 and 5F in U2OS cells), which was reversed by LEDGF/p75 
re-expression but not LEDGF/p52. This indicates a direct or an indirect role of LEDGF/p75 on the expression of UBC13 and PA28 $\gamma$, which in turn might affect $\gamma \mathrm{H} 2 \mathrm{AX}$ and BRCA1 degradation. In Figure 5G, we propose how LEDGF might regulate HDR-mediated DNA repair in addition to the recruitment of CtIP due to the changing UBC13 and PA28 $\gamma$ levels.

A.

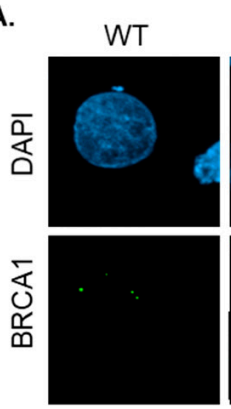

c.

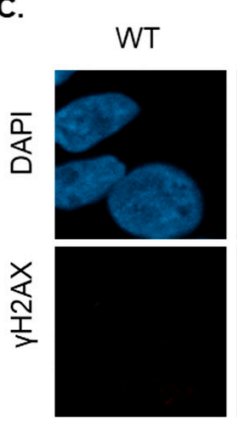

E.
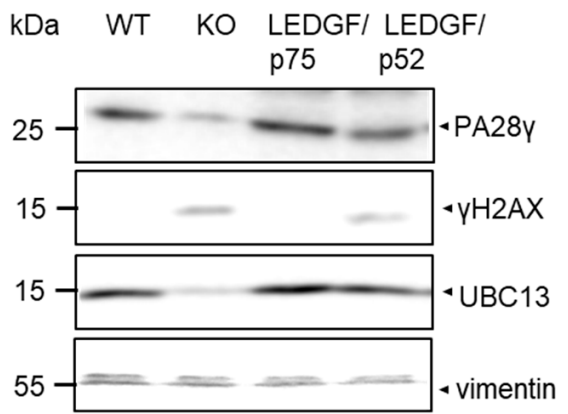

B.

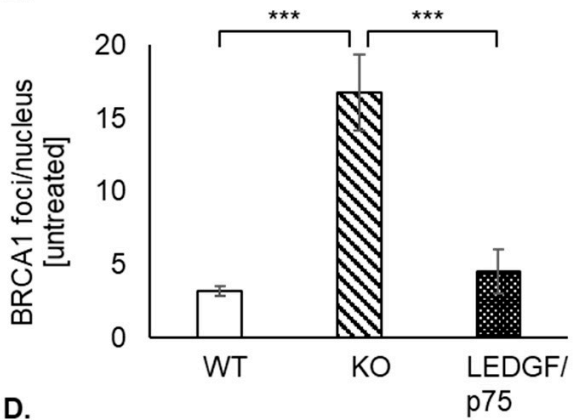

D.

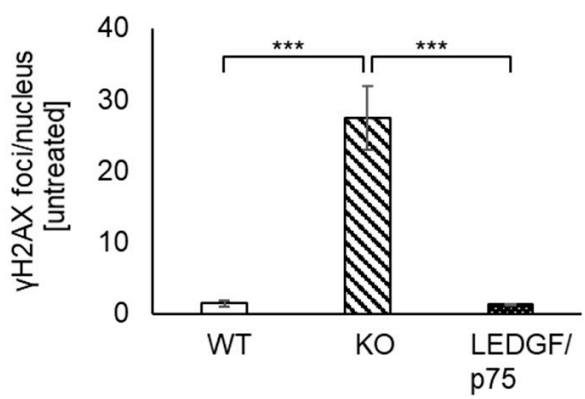

F.

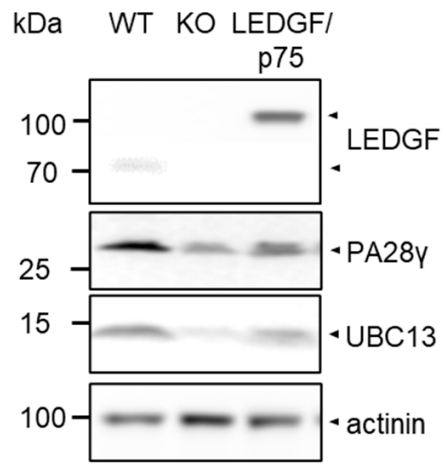

G.

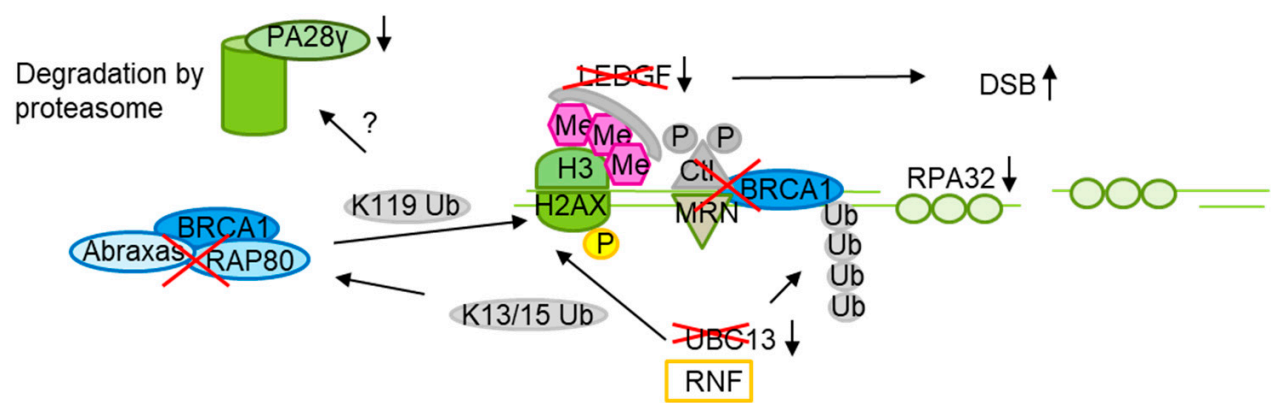

Figure 5. LEDGF depletion causes dysregulation of DNA damage response. (A,C) Representative confocal images of BRCA1 foci (A) and $\gamma \mathrm{H} 2 \mathrm{AX}$ foci (C) of untreated HEp-2 WT, LEDGF KO, and LEDGF/p75 re-expressing cells are shown after fixation with $2 \%$ formaldehyde and incubation with anti- $\gamma \mathrm{H} 2 \mathrm{AX}$ or anti-BRCA1. Chromatin appears blue due to DAPI incorporation, BRCA1 (green), and $\gamma \mathrm{H} 2 \mathrm{AX}$ (red). Scale bar: $10 \mu \mathrm{m}$. (B,D) Analysis of BRCA1 foci (pWT-KO = 0.0005, 
pKO-p75 = 0.0008, pWT-p75 = 0.8100) $(\mathbf{B})$ and $\gamma \mathrm{H} 2 \mathrm{AX}$ foci $\left(\mathrm{pWT}-\mathrm{KO}=10^{-7}, \mathrm{pKO}-\mathrm{p} 75=10^{-7}, \mathrm{pWT}-\mathrm{p} 75=0.9934\right)(\mathbf{D})$ in HEp-2 WT, LEDGF KO, and LEDGF/p75 re-expressing cells using NucDetect software, $n=3$. ${ }^{* *} p<0.00$. (E) Untreated HEp2 cell lines were harvested after $48 \mathrm{~h}$ and protein extracts were analyzed by immunoblotting using antibodies against PA28 $\gamma$, $\gamma \mathrm{H} 2 \mathrm{AX}, \mathrm{UBC} 13$, and vimentin as loading control. (F) Untreated U2OS cell lines were analyzed by immunoblotting. Vimentin was used as loading control. (G) Scheme of the HDR-mediated DDR signaling in LEDGF KO cells after DSB. LEDGFdependent activation of CtlP is interrupted, allowing no complex formation with MRN and BRCA1 and subsequently no activation of RPA32 and later Rad51, resulting in ineffective DNA end resection. Due to UBC13 downregulation, K63-linked ubiquitination to lysine residues (K13/15) of $\gamma \mathrm{H} 2 \mathrm{AX}$ molecules are most likely missing. Without these ubiquitination signals, the BRCA1-A complex (containing also Rap80 and Abraxas) is unable to coordinate the release of $\gamma \mathrm{H} 2 \mathrm{AX}$ (ubiquitination at K119) from the chromatin. Consequently, degradation by the proteasome (in the nucleus PA28 $\gamma$ ) is also impaired, leading to persistent $\gamma \mathrm{H} 2 \mathrm{AX}$ foci.

\section{Discussion}

LEDGF/p75 has been reported to be overexpressed in different solid tumors and cancer cell lines [10]. Particularly, it is involved in cancer progression by controlling the expression of genes regulating the cell cycle, cell proliferation, and survival [22]. Furthermore, LEDGF/p75 is supposed to enhance HDR by promoting CtIP-BRCA1-dependent DNA endresection after DNA DSB and influences the recruitment of DNA-damage response-related downstream proteins such as RPA32 [21]. Instead of siRNA knockdown with potential residual LEDGF expression, we generated complete PSIP1 knockout using CRISPR/Cas9 technology. We show for the first time that complete LEDGF depletion has an essential influence on DDR signaling.

Firstly, we generated LEDGF KO cell lines. To avoid off-target effects due to plasmid integration and constitutive active Cas9 expression, LEDGF knockout generation was pursued using EGFP reporter expression to enrich cells transiently expressing Cas9 and sgRNA. Thus, effects detectable for EGFP-selected LEDGF KO clones should be based on LEDGF knockout, making the results more reliable. Potential off-target effects due to the sgRNA [23] were checked by sequencing (Figure S1E). Additionally, different LEDGF $\mathrm{KO}$ clones were tested for their uniform behavior using a proliferation assay (Figure S2A). Moreover, LEDGF recovery experiments showed that the effects induced by LEDGF depletion could be rescued by EGFP-LEDGF/p75 re-expression, indicating a specific knockout.

Increased LEDGF/p75 expression in prostate cancer [24], breast cancer [22], or colon cancer [1] was linked with an aggressive tumor phenotype. Furthermore, the upregulation of LEDGF in prostate and breast cancer cell lines has been shown to play a role in proliferation, migration, and chemoresistance [12,22]. Migration and invasion is an important step in cancer metastasis [25]; however, the involvement of LEDGF in this dynamic process remains unclear. In the presented study, proliferation and migration analysis of LEDGF depleted cells (Figures 2 and 3) showed a significant reduction in cell growth and decreased migration ability, supporting LEDGF's involvement in pro-survival pathways as previously described [12]. This is further underlined by the LEDGF/p75 o/e model in our study where increased expression resulted in enhanced migratory abilities (Figure 2C). Moreover, these cells showed a change in morphology to a fibroblast-like phenotype, which was accompanied with an increased expression of $\alpha$-tubulin. Up to now, only acetylation of $\alpha$-tubulin has been connected to cancer cell migration and invasion [26,27]. However, increased class III $\beta$-tubulin has been associated with a more aggressive tumor phenotype [28]. Taking into account both the increased migration capacity and the changed morphology in consideration, we suggest that LEDGF o/e leads to a more aggressive and invasive cancer phenotype.

The role of LEDGF in DDR signaling should be investigated. Therefore, we induced DNA DSB using the topoisomerase etoposide. Interestingly, LEDGF depletion sensitizes cells toward caspase-dependent cell death on etoposide exposure [12]. In this work, the characterization of LEDGF KO clones confirmed a direct correlation of LEDGF depletion with a reduced proliferation and an increased sensitivity toward topoisomerase II inhibition by etoposide. 
As previously shown elsewhere $[6,21,29]$, the re-expression of the shorter splice variant LEDGF/p52 has no enhancing effect on the cell proliferation, migration, or chemosensitivity.

Daugaard et al. [21] demonstrated LEDGF as an important factor in DNA repair via HDR. After induction of a DNA DSB, the ensuing cellular damage response leads either to NHEJ or HDR. In contrast to NHEJ, HDR is only active in late S- and G2-phase [30]. Moreover, LEDGF KO cells exhibit a decreased survival and elevated DNA fragmentation upon etoposide exposure, which might indicate a deficiency to repair DNA DSBs by HDR. Therefore, RPA32 foci formation was investigated, and indeed, in LEDGF knockout clones, less RPA32 was recruited to the DNA damage sites in comparison to the wildtype cells. In fact, LEDGF/p75 is known to bind to methylated histones, supporting the binding of $\mathrm{C}$-terminal binding protein (CtBP) interacting protein (CtIP), which assists DNA damage recognition by the MRN complex [21]. Subsequently, this activates three main damage response-related protein kinases: ATM, ATR, and DNA PKs. RPA32, also active during replication, is activated by ATM and ATR, resulting in phosphorylated RPA32 foci formation, which is necessary for the recruitment of downstream DNA repair proteins [31].

The reduced amount of RPA32 foci in LEDGF-KO clones is consistent with the results of Daugaard et al. [21], which implies that LEDGF is necessary for the recruitment of HDR-related DNA repair proteins and is required for an efficient DNA repair. In addition to the drug-induced DNA damage, elevated $\gamma \mathrm{H} 2 \mathrm{AX}$ foci formation was already detected upon LEDGF KO, suggesting that LEDGF plays a role in the maintenance of genome stability. In fact, SETD2 depletion resulted also in an increased $\gamma \mathrm{H} 2 \mathrm{AX}$ foci formation [32] SETD2 trimethylates histone-3 lysine-36 (H3K36me3) at sites of active transcription where the histone code reader LEDGF/p75 binds to it [13]. Furthermore, persistent $\gamma \mathrm{H} 2 \mathrm{AX}$ is an indicator for "oncogenic stress", DNA damage driving genomic instability or malignant conversion [33]. Chromosomal instability and gene mutations in cancer cells are well described (reviewed in [34]) and are often caused by increased DNA DSBs with dysregulated DNA repair mechanisms. Since LEDGF/p75 is involved in the HDR-mediated DNA repair, its depletion might leave more DNA DSBs unrepaired. In cancer cells, spontaneous DNA damage foci formation (increase in $\gamma \mathrm{H} 2 \mathrm{AX}$ foci formation) caused by self-inflicting or endogenous DNA DSBs are often observed. We were able to show that in LEDGF KO cells, those endogenous DNA DSBs are significantly increased (Figure 4B). Moreover, LEDGF $\mathrm{KO}$ cells exhibited elevated $\gamma \mathrm{H} 2 \mathrm{AX}$ as well as BRCA1 foci, which are both known as DNA damage sensors $[15,35]$. Controversially, LEDGF KO cells could be continuously cultured (with decreased proliferation) and are not prone to go directly into complete cell death which suggests that LEDGF interacts with further signaling pathways.

Finally, increased phosphorylation of H2AX can be also caused in response to cell cycle progression during G2/M phase entry [36]. Furthermore, elevated $\gamma \mathrm{H} 2 \mathrm{AX}$ and G2/M arrest could also be indicators for senescence [37,38]. Therefore, a potential cell cycle arrest in LEDGF KO cells was investigated, especially because LEDGF knockdown has been previously shown to induce cell cycle arrest in the S/G2 phase and increased apoptosis in prostate cancer cells [10]. Nonetheless, in our study, cell cycle profiles of WT and LEDGF-depleted cells were similar without any sign of cell arrest in LEDGF KO cells (Figure S2B). As we could not detect a cell cycle arrest but an increased chemosensitivity, we excluded the possibility that the $\gamma \mathrm{H} 2 \mathrm{AX}$ foci are senescence related.

Since the persistent DNA fragmentation in LEDGF KO cells still allows proliferation, we investigated whether the persistently high $\gamma \mathrm{H} 2 \mathrm{AX}$ could be also related to an insufficient degradation of the $\gamma \mathrm{H} 2 \mathrm{AX}$. An efficient and coordinated degradation of signaling molecules is necessary for an efficient DDR, which is also accompanied by a vast amount of proteasome-independent K63-linked ubiquitin modifications of the signaling molecules. The protein ubiquitylation plays a central role orchestrating the DDR, whereby K63 linkages promote protein recruiting and K48 linkages destabilize the protein (degradation) [39]. At the end of the signal transduction, many DDR-involved molecules e.g., $\gamma \mathrm{H} 2 \mathrm{AX}$, are degraded by the proteasome $[16,40,41]$. Interestingly, it has been shown that the knockout of the nuclear proteasome activator PA28 $\gamma$ led to persistent $\gamma \mathrm{H} 2 \mathrm{AX}$ foci, even after signal 
termination [20]. These persistent $\gamma \mathrm{H} 2 \mathrm{AX}$ foci interfere with new DNA damage signals, which lead to an overall reduced DDR and thus to genetically unstable cells. Consequently, LEDGF-depleted cells were investigated for their PA28 $\gamma$ expression, and indeed, PA28 $\gamma$ protein levels were decreased. As demonstrated for PA28 $\gamma$ knockout cells, LEDGF depletion also resulted in a decreased PA28 $\gamma$ protein level. This might indicate that the sustained $\gamma \mathrm{H} 2 \mathrm{AX}$ foci and BRCA1 foci are also a result of the diminished degradation of these molecules. Moreover, the proteasome recycles ubiquitin by degrading proteins, which is required indirectly for the ubiquitin signaling in DDR, as it supplies the DNA repair ligases e.g., UBC13 with ubiquitin [42]. However, an effect of limited ubiquitin is very speculative and has been investigated in this study. Nonetheless, UBC13 has been previously suggested to ubiquitinate $\gamma \mathrm{H} 2 \mathrm{AX}$ molecules, which subsequently allows the binding of BRCA1 to initiate the degradation of $\gamma \mathrm{H} 2 \mathrm{AX}$ [43]. Therefore, the UBC13 expression was also verified in the LEDGF KO cells and as expected UBC13 protein levels were abrogated (Figure 5). A possible scenario how the LEDGF KO affects the HR-mediated DDR was illustrated in Figure 5G.

In the past, LEDGF was only known to recruit the DDR protein CtIP; however, here, we show for the first time that LEDGF seems to have an indirect or direct effect on regulatory proteins of the DDR such as UBC13 and PA28 $\gamma$, which are known to be involved, e.g., in the degradation of $\gamma \mathrm{H} 2 \mathrm{AX}$.

\section{Materials and Methods}

\subsection{Antibodies}

The following antibodies were used in this study: Anti-RPA32 (9H8), anti-N-PSIP1, anti-BRCA1 (G-9), UBC13 (F-10) (Santa Cruz Biotechnology, Dallas, TX, USA), anti-CLEDGF/p75 (Bethyl-Laboratories, Montgomery, TX, USA), anti- $\gamma$ H2AX (Cell Signaling, Danvers, MA, USA), anti-PA28 $\gamma$ (K5.6), $\alpha$-Mouse-IgG-Atto 488 N (Sigma Aldrich, St. Louis, MO, USA), $\alpha$-rabbit-IgG-Atto 647 (Dianova, Hamburg, Germany), anti-mouse-IgGk BPHRP (Santa Cruz Biotechnology, Dallas, TX, USA), and anti-rabbit HRP (Sigma Aldrich, St. Louis, MO, USA).

\subsection{Cell Lines and Culture}

Human epithelial type 2 (HEp-2) and human bone osteosarcoma epithelial cells (U2OS) wild-type (WT) cells as well as LEDGF knockout (KO), EGFP-LEDGF/p75 reexpressing (LEDGF/p75), and mEmarald_LEDGF/p52 re-expressing (LEDGF/p52) cells were grown up to $80 \%$ confluence in DMEM/Ham's F12 supplemented with 10\% FBS (Biowest, Nuaillé, France), 2 mM L-glutamine (Merck Millipore, Burlington, MA, USA), and penicillin/streptomycin (Merck Millipore, Burlington, MA, USA) in a humidified incubator at $37^{\circ} \mathrm{C}$ and $5 \% \mathrm{CO}_{2}$. WT and LEDGF/p75 cell lines were split in a 1:10 ratio, LEDGF KO cells were split in a 1:5 ratio.

\subsection{Cloning}

For the generation of LEDGF KO cells, sgRNA_DF70_E1 (AGATGAAAGGTTATCCCCAT, targeting exon 1 of PSIP1 gene) was cloned into pSpCas9(BB)-2A-GFP (PX458; Addgene plasmid \# 48138), kindly provided by Feng Zhang, Ph.D. [44]. Plasmids for EGFPLEDGF/p75 overexpression (o/e) were created by cloning sgRNA_AAVS1 (CCAATCCTGTCCCTAG, targeting AAVS1 locus) into pSpCas9(BB)-2A-GFP and gBlock HDR fragment (attB-sites, EGFP-LEDGF/p75 coding sequence, Figure S5) into pAAVS1-P-CAGDEST (Addgene plasmid \#80490), kindly provided by Knut Woltjen, Ph.D. [45]. Plasmid for LEDGF/p52 o/e was created by cloning gBlock HDR fragment (attB-sites, mEmarald_LEDGF/p52 coding sequence, Figure S6) into pAAVS1-P-CAG-DEST as described in the GATEWAY Cloning Technology Instruction Manual. 


\subsection{Generation of LEDGF-Modified Cell Clones}

HEp-2 WT and U2OS WT cells were seeded in 6-well plates (TH. Geyer, Renningen, Germany), incubated for $24 \mathrm{~h}$, and subsequently transfected with px458_sgR_DFS70_E1 using LipofectamineTM 3000 according to the manufacturer's instructions (Thermo Fisher Scientific, Waltham, MA, USA). For the EGFP-LEDGF/p75 o/e, WT and LEDGF KO cells were co-transfected with px458_sgRNA_AAVS1 and pAAVS1_CAG-EGFP-LEDGF/p75. The generation of mEmarald_LEDGF/p52 o/e cells was performed using px458_sgRNA_AAVS1 and pAAVS1_CAG-mEmarald_LEDGF/p52. Transfected cells were enriched by the EGFP selection of biomarkers via FACS using the S3e cell sorter (Bio-Rad). Briefly, cells were resuspended in $1 \times$ PBS supplemented with $0.5 \%$ FBS, while doublet cells were excluded by bivalent plotting of FSC and SSC, and positively transfected cells were sorted by GFP expression. Per $10 \mathrm{~cm}^{2}$ cell culture plate, a total of $1 \times 10^{3}$ cells were seeded. Outgrown fluorescent, single cell colonies were picked after 7-10 days to establish LEDGF o/e cell lines. Subsequently, the cell clones were analyzed to verify the integration of the expression cassette at the AAVS1 locus was verified by PCR as described in Oceguera-Yanez [45], showing only heterozygous integrations. Subsequently, the expression of LEDGF was verified by Western blot, which exhibited different LEDGF expressions. Therefore, one cell clone expressing WT LEDGF and one LEDGF o/e was selected for the study.

\subsection{Proliferation Analysis}

To determine cell proliferation, cells were seeded at a density of $5 \times 10^{3}$ cells/well in a 96-well plate (Th.Geyer, Renningen, Germany), and sulforhodamine B (SRB) assay was performed according to nature protocol [46].

\subsection{Exposure to Etoposide}

Cells were seeded at $5 \times 10^{3}$ cells/well into 96-well plates (Th.Geyer, Renningen, Germany) and incubated for $24 \mathrm{~h}$. Subsequently, cells were exposed to different levels of etoposide (between $2.5-20 \mu \mathrm{M}$ ).

\subsection{Digital Image Analysis and Bioimage Informatics}

Analysis of cell viability was performed using a fully automated multispectral fluorescence microscopy VideoScan platform [47,48]. Cells were stained with DAPI $(2 \mu \mathrm{g} / \mathrm{mL}$, Merck Millipore, Burlington, MA, USA) in $1 \times$ PBS (Biowest, Nuaillé, France) and incubated $15 \mathrm{~min}$ at $37^{\circ} \mathrm{C}, 5 \% \mathrm{CO}_{2}$, following VideoScan analysis with exposure time of $0.5-1 \mathrm{~s}$. Cell count per image was measured via Blob detection as implemented in scikit-image (blob_log; v.0.17.2) [25] Images were further analyzed using bioimage informatics by Python 3.7 script as described elsewhere [25,49].

Cell morphology was analyzed via calculation of the roundness and eccentricity of each cell. For that, firstly, each cell with its corresponding nuclei was extracted as a set of points via thresholding (1.96\% of maximum possible pixel intensity) and extraction of foreground pixels. Under-segmented areas were detected via the overlap of multiple nuclei with one area. Each region containing multiple nuclei was segmented via a seeded flood fill approach. Thereby, the centers of all corresponding nuclei were used as seed points for segmentation. Cell eccentricity was calculated via the second-order area moments. Roundess $\mathrm{R}$ was estimated as the normalized ratio between area $\mathrm{A}$ and perimeter $\mathrm{P}$ of the cell by the equation $\mathrm{R}=(4 * \pi * \mathrm{~A}) / \mathrm{P}$.

The morphology of cells was separated into normal and fibroblast-like via DensityBased Spatial Clustering of Applications with Noise (DBSCAN) clustering as implemented in the Python 3.7 package scikit-learn v. 0.23.1 (eps $=0.15$, min_samples $=45)$.

\subsection{Scratch Assay}

For measuring in vitro migration, $1 \times 10^{5}$ cells/well were seeded in 48 -well plates (Sarstedt, Nümbrecht, Germany) and incubated for $24 \mathrm{~h}$. To stop proliferation, cells were treated with mitomycin C ( $10 \mu \mathrm{g} / \mathrm{mL}$, abcr GmbH, Karlsruhe, Germany) for $2 \mathrm{~h}$; then, they 
were washed and incubated for $22 \mathrm{~h}$ at $37{ }^{\circ} \mathrm{C}, 5 \% \mathrm{CO}_{2}$. Circular scratches were created using a $100 \mu \mathrm{L}$ pipette tip and measured after $0 \mathrm{~h}$ and $24 \mathrm{~h}$. Scratch areas were analyzed using ImageJ-macro MRI_would_healing_tool (http:/ / dev.mri.cnrs.fr / projects /imagejmacros/wiki/Wound_Healing_Tool, accessed on 14 December 2019).

\subsection{Immunofluorescence}

Cells were seeded at $5 \times 10^{3}$ cells/well on 10-well slides (Hecht Assistant, Sondheim v. d. Rhön, Germany) and incubated for $24 \mathrm{~h}$. For analysis, cells were fixed with $2 \%$ formaldehyde for 15 min at RT and permeabilized with 0.3\% Triton X-100 (AppliChem, Darmstadt, Germany) while blocking with 5\% BSA/PBS. Primary antibody was added and incubated at RT for $1 \mathrm{~h}$. Slides were washed with $1 \times$ PBS and then incubated with secondary antibody and DAPI $(2.5 \mathrm{mg} / \mathrm{mL}, 1: 500)$ for $1 \mathrm{~h}$ in the dark at RT. Fluorophore photostability was increased by coating slides with mounting medium (Roti ${ }^{\circledR}$-Mount FluorCare, Carl Roth $\mathrm{GmbH}$, Karlsruhe, Germany). Analysis was performed using a confocal laser scanning microscope LSM 800 (Zeiss, Oberkochen, Germany). Foci formation (250-500 nuclei/image) was analyzed using NucDetect software, excluding mitotic cells (NucDetect 0.11.14, written in Python 3.7, available at https://pypi.org/project/NucDetect/, accessed on 25 March 2021).

\subsection{Immunoblotting}

Cells $\left(1 \times 10^{6}\right)$ were harvested and resuspended in $50 \mu \mathrm{L} 2 \times$ Lämmli-buffer, and protein content was determined using a Pierce ${ }^{\mathrm{TM}}$ BCA Protein Assay Kit (Thermo Fisher Scientific, Waltham, MA, USA). Immunoblotting was performed using standard protocols [50]. Antibodies were diluted in 5\% milk powder or 5\% BSA (Carl Roth, Karlsruhe, Germany) in TBS/0.1\% Tween-20 (AppliChem, Darmstadt, Germany). The band intensity was quantified by ImageJ software (1.53c 26).

\subsection{Pulsed Field Gel Electrophoresis (PFGE)}

Cells were seeded at $2 \times 10^{6}$ cells $/ 10 \mathrm{~cm}$ dish and incubated for $24 \mathrm{~h}$. Cells were treated as indicated, harvested, cell pellets were resuspended in $1 \times$ PBS/peqGOLD agarose (VRW, Erlangen, Germany) (1:1) and used to cast inserts. Inserts were solidified at $4{ }^{\circ} \mathrm{C}$ and then incubated in ESP buffer (0.5 M EDTA (Carl Roth, Karlsruhe, Germany), 1\% $(w / v)$ N-laurylsarcosine (Carl Roth, Karlsruhe, Germany)) supplemented with $1.8 \mathrm{mg} / \mathrm{mL}$ proteinase $\mathrm{K}$ ( $\leq 30 \mathrm{mAnson} \mathrm{U} / \mathrm{mg}$, Carl Roth, Karlsruhe, Germany) at $56{ }^{\circ} \mathrm{C}$ for $18-20 \mathrm{~h}$. Inserts were washed twice in $1 \times \mathrm{TE}$ buffer for $2 \mathrm{~h}$ at $4{ }^{\circ} \mathrm{C}, 10 \mathrm{rpm}$. Inserts were transferred to a $1.2 \%$ peqGOLD agarose (VWR, Darmstadt, Germany) gel in $0.5 \times$ TBE buffer $(44.5 \mathrm{mM}$ Tris-borate and $1 \mathrm{mM}$ EDTA $(\mathrm{pH} \mathrm{8.3)})$ and run at $6 \mathrm{~V} / \mathrm{cm}, 5-50 \mathrm{~s}$ switch time for $22 \mathrm{~h}$ at $14{ }^{\circ} \mathrm{C}$ in PFGE chamber (Bio-Rad Genepath Electrophoresis Gel Cell, Bio-Rad, Hercules, CA, USA).

\subsection{Statistical Analysis}

All data were statistically analyzed with the statistical computing language R v. 3.6 (R: The R Project for Statistical Computing, 2020 [51]). The Kolmogorov-Smirnov test was used for testing normal distribution. To control the $\alpha$ error inflation, the Bonferroni correction is applied or Tukey's HSD test is used to test the differences between the mean values of the sample for significance. $p$-values less than 0.05 were considered significant. Experiments were conducted with at least three biological replicates. Data were further analyzed using RKWard v. 0.7.1z + 0.7.2 + devel2 [47] for the R statistical computing environment. Dose-response curves were fitted (95\% confidence interval) with multiparametric functions (EXD3: Three-parameter exponential decay model; LL4: Four-parameter log-logistic model) from the drc package [52]. The optimal model was selected by using the AIC (Akaike information criterion) as criterion. 
Supplementary Materials: The following are available online at https://www.mdpi.com/article/10 $.3390 /$ ijms22115866/s1.

Author Contributions: Conceptualization, V.L., C.S., S.R. and L.S.; methodology, V.L., C.S. and L.S.; software, R.W. and S.R.; validation, S.R. and L.S., formal analysis, S.R.; investigation, V.L.; resources, C.S., P.S., S.R. and L.S.; data curation, V.L.; writing-original draft preparation, V.L.; writing-review and editing, D.R., R.S., S.R. and L.S.; visualization, V.L.; supervision, L.S.; project administration, L.S.; funding acquisition, P.S., S.R. and L.S. All authors have read and agreed to the published version of the manuscript.

Funding: This work was supported by the "Gesundheitscampus Brandenburg-Konsequenzen der altersassoziierten Zell-und Organfunktionen" [GeCa: H228-05/002/008, 2017-2019] initiative of the Ministry of Science, Research and Culture of Brandenburg (MWFK, Germany), PRAEMED.BIOPräzisionsmedizin durch biomarkerbasierte Diagnostik of the Federal Ministry of Education and Research (03WKDB2C, BMBF, Germany) and the Friedrich-Naumann Foundation for Freedom.

Institutional Review Board Statement: Not applicable.

Informed Consent Statement: Not applicable.

Data Availability Statement: The data that support the findings of this study are available from the corresponding author upon reasonable request.

Acknowledgments: We would like to thank Madeleine Ruhe, Franziska Dinter and Julia Engelmann for their support during the conduction of experiments.

Conflicts of Interest: The authors declare no conflict of interest.

\section{References}

1. Basu, A.; Woods-Burnham, L.; Ortiz, G.; Rios-Colon, L.; Figueroa, J.; Albesa, R.; Andrade, L.E.; Mahler, M.; Casiano, C.A. Specificity of Antinuclear Autoantibodies Recognizing the Dense Fine Speckled Nuclear Pattern: Preferential Targeting of DFS70/LEDGFp75 over Its Interacting Partner MeCP2. Clin. Immunol. 2015, 161, 241-250. [CrossRef]

2. Debyser, Z.; Christ, F.; De Rijck, J.; Gijsbers, R. Host Factors for Retroviral Integration Site Selection. Trends Biochem. Sci. 2015, 40, 108-116. [CrossRef]

3. Leitz, J.; Reuschenbach, M.; Lohrey, C.; Honegger, A.; Accardi, R.; Tommasino, M.; Llano, M.; von Knebel Doeberitz, M.; Hoppe-Seyler, K.; Hoppe-Seyler, F. Oncogenic Human Papillomaviruses Activate the Tumor-Associated Lens Epithelial-Derived Growth Factor (LEDGF) Gene. PLoS Pathog. 2014, 10, e1003957. [CrossRef] [PubMed]

4. Basu, A.; Rojas, H.; Banerjee, H.; Cabrera, I.B.; Perez, K.Y.; De León, M.; Casiano, C.A. Expression of the Stress Response Oncoprotein LEDGF/P75 in Human Cancer: A Study of 21 Tumor Types. PLoS ONE 2012, 7, e30132. [CrossRef] [PubMed]

5. Daniels, T.; Zhang, J.; Gutierrez, I.; Elliot, M.L.; Yamada, B.; Heeb, M.J.; Sheets, S.M.; Wu, X.; Casiano, C.A. Antinuclear Autoantibodies in Prostate Cancer: Immunity to LEDGF/P75, a Survival Protein Highly Expressed in Prostate Tumors and Cleaved during Apoptosis. Prostate 2005, 62, 14-26. [CrossRef] [PubMed]

6. Brown-Bryan, T.A.; Leoh, L.S.; Ganapathy, V.; Pacheco, F.J.; Mediavilla-Varela, M.; Filippova, M.; Linkhart, T.A.; Gijsbers, R.; Debyser, Z.; Casiano, C.A. Alternative Splicing and Caspase-Mediated Cleavage Generate Antagonistic Variants of the Stress Oncoprotein LEDGF/P75. Mol. Cancer Res. 2008, 6, 1293-1307. [CrossRef]

7. Pradeepa, M.M.; Sutherland, H.G.; Ule, J.; Grimes, G.R.; Bickmore, W.A. Psip1/Ledgf P52 Binds Methylated Histone H3K36 and Splicing Factors and Contributes to the Regulation of Alternative Splicing. PLoS Genet. 2012, 8, e1002717. [CrossRef]

8. Ochs, R.L.; Mahler, M.; Basu, A.; Rios-Colon, L.; Sanchez, T.W.; Andrade, L.E.; Fritzler, M.J.; Casiano, C.A. The Significance of Autoantibodies to DFS70/LEDGFp75 in Health and Disease: Integrating Basic Science with Clinical Understanding. Clin. Exp. Med. 2016, 16, 273-293. [CrossRef]

9. Ishihara, K.; Fatma, N.; Bhargavan, B.; Chhunchha, B.; Kubo, E.; Dey, S.; Takamura, Y.; Kumar, A.; Singh, D.P. Lens EpitheliumDerived Growth Factor DeSumoylation by Sumo-Specific Protease-1 Regulates Its Transcriptional Activation of Small Heat Shock Protein and the Cellular Response: Senp-1 Regulates LEDGF Transcriptional Activity. FEBS J. 2012, 279, 3048-3070. [CrossRef]

10. Bhargavan, B.; Fatma, N.; Chhunchha, B.; Singh, V.; Kubo, E.; Singh, D.P. LEDGF Gene Silencing Impairs the Tumorigenicity of Prostate Cancer DU145 Cells by Abating the Expression of Hsp27 and Activation of the Akt/ERK Signaling Pathway. Cell Death Dis. 2012, 3, e316. [CrossRef]

11. Fatma, N.; Singh, D.P.; Shinohara, T.; Chylack, L.T. Transcriptional Regulation of the Antioxidant Protein 2 Gene, a Thiol-Specific Antioxidant, by Lens Epithelium-Derived Growth Factor to Protect Cells from Oxidative Stress. J. Biol. Chem. 2001, 276, 48899-48907. [CrossRef]

12. Ríos-Colón, L.; Ross, C.K.C.-D.; Basu, A.; Elix, C.; Alicea-Polanco, I.; Sanchez, T.W.; Radhakrishnan, V.; Chen, C.-S.; Casiano, C.A. Targeting the Stress Oncoprotein LEDGF/P75 to Sensitize Chemoresistant Prostate Cancer Cells to Taxanes. Oncotarget 2017, 8, 24915. [CrossRef] 
13. Li, L.; Wang, Y. Cross-Talk between the H3K36me3 and H4K16ac Histone Epigenetic Marks in DNA Double-Strand Break Repair. J. Biol. Chem. 2017, 292, 11951-11959. [CrossRef]

14. Tang, J.; Cho, N.W.; Cui, G.; Manion, E.M.; Shanbhag, N.M.; Botuyan, M.V.; Mer, G.; Greenberg, R.A. Acetylation Limits 53BP1 Association with Damaged Chromatin to Promote Homologous Recombination. Nat. Struct. Mol. Biol. 2013, 20, 317-325. [CrossRef]

15. Wang, Y.; Cortez, D.; Yazdi, P.; Neff, N.; Elledge, S.J.; Qin, J. BASC, a Super Complex of BRCA1-Associated Proteins Involved in the Recognition and Repair of Aberrant DNA Structures. Genes Dev. 2000, 14, 927-939.

16. Gruosso, T.; Mieulet, V.; Cardon, M.; Bourachot, B.; Kieffer, Y.; Devun, F.; Dubois, T.; Dutreix, M.; Vincent-Salomon, A.; Miller, K.M.; et al. Chronic Oxidative Stress Promotes H2 AX Protein Degradation and Enhances Chemosensitivity in Breast Cancer Patients. EMBO Mol. Med. 2016, 8, 527-549. [CrossRef]

17. Kim, S.; Jin, H.; Seo, H.-R.; Lee, H.J.; Lee, Y.-S. Regulating BRCA1 Protein Stability by Cathepsin S-Mediated Ubiquitin Degradation. Cell Death Differ. 2019, 26, 812-825. [CrossRef]

18. Densham, R.M.; Garvin, A.J.; Stone, H.R.; Strachan, J.; Baldock, R.A.; Daza-Martin, M.; Fletcher, A.; Blair-Reid, S.; Beesley, J.; Johal, B.; et al. Human BRCA1-BARD1 Ubiquitin Ligase Activity Counteracts Chromatin Barriers to DNA Resection. Nat. Struct. Mol. Biol. 2016, 23, 647-655. [CrossRef]

19. Mallery, D.L. Activation of the E3 Ligase Function of the BRCA1/BARD1 Complex by Polyubiquitin Chains. EMBO J. 2002, 21, 6755-6762. [CrossRef]

20. Levy-Barda, A.; Lerentha, Y.; Davis, A.J.; Chung, Y.M.; Essers, J.; Shao, Z.; van Vliet, N.; Che, D.J.; Hu, M.C.-T.; Kanaar, R.; et al. Involvement of the Nuclear Proteasome Activator PA28 $\gamma$ in the Cellular Response to DNA Doublestrand Break. Cell Cycle 2011. [CrossRef]

21. Daugaard, M.; Baude, A.; Fugger, K.; Povlsen, L.K.; Beck, H.; Sørensen, C.S.; Petersen, N.H.T.; Sorensen, P.H.B.; Lukas, C.; Bartek, J.; et al. LEDGF (P75) Promotes DNA-End Resection and Homologous Recombination. Nat. Struct. Mol. Biol. 2012, 19, 803-810. [CrossRef]

22. Singh, D.K.; Gholamalamdari, O.; Jadaliha, M.; Ling Li, X.; Lin, Y.-C.; Zhang, Y.; Guang, S.; Hashemikhabir, S.; Tiwari, S.; Zhu, Y.J.; et al. PSIP1/P75 Promotes Tumorigenicity in Breast Cancer Cells by Promoting the Transcription of Cell Cycle Genes. Carcinogenesis 2017, 38, 966-975. [CrossRef] [PubMed]

23. Zhang, X.-H.; Tee, L.Y.; Wang, X.-G.; Huang, Q.-S.; Yang, S.-H. Off-Target Effects in CRISPR/Cas9-Mediated Genome Engineering. Mol. Ther. Nucleic Acids 2015, 4, e264. [CrossRef]

24. Mediavilla-Varela, M.; Pacheco, F.J.; Almaguel, F.; Perez, J.; Sahakian, E.; Daniels, T.R.; Leoh, L.; Padilla, A.; Wall, N.R.; Lilly, M.B.; et al. Docetaxel-Induced Prostate Cancer Cell Death Involves Concomitant Activation of Caspase and Lysosomal Pathways and Is Attenuated by LEDGF/P75. Mol. Cancer 2009, 8, 68. [CrossRef] [PubMed]

25. SilMon. SilMon/Cell-Morphology-Notebook: V. 1.1 (Version v1.1). Zenodo. Available online: http://doi.org/10.5281/zenodo.42 71745 (accessed on 13 November 2020).

26. Boggs, A.E.; Vitolo, M.I.; Whipple, R.A.; Charpentier, M.S.; Goloubeva, O.G.; Ioffe, O.B.; Tuttle, K.C.; Slovic, J.; Lu, Y.; Mills, G.B.; et al. $\alpha$-Tubulin Acetylation Elevated in Metastatic and Basal-like Breast Cancer Cells Promotes Microtentacle Formation, Adhesion, and Invasive Migration. Cancer Res. 2015, 75, 203-215. [CrossRef]

27. Lee, C.-C.; Cheng, Y.-C.; Chang, C.-Y.; Lin, C.-M.; Chang, J.-Y. Alpha-Tubulin Acetyltransferase/MEC-17 Regulates Cancer Cell Migration and Invasion through Epithelial-Mesenchymal Transition Suppression and Cell Polarity Disruption. Sci. Rep. 2018, 8. [CrossRef]

28. Lebok, P.; Öztürk, M.; Heilenkötter, U.; Jaenicke, F.; Müller, V.; Paluchowski, P.; Geist, S.; Wilke, C.; Burandt, E.; Lebeau, A.; et al. High Levels of Class III $\beta$-Tubulin Expression Are Associated with Aggressive Tumor Features in Breast Cancer. Oncol. Lett. 2016, 11, 1987-1994. [CrossRef]

29. Huang, T.; Myklebust, L.M.; Kjarland, E.; Gjertsen, B.; Pendino, F.; Bruserud, Ø.; Døskeland, S.; Lillehaug, J.R. LEDGF/P75 Has Increased Expression in Blasts from Chemotherapy-Resistant Human Acute Myelogenic Leukemia Patients and Protects Leukemia Cells from Apoptosis in Vitro. Mol. Cancer 2007, 6, 31. [CrossRef]

30. Lin, S.; Staahl, B.T.; Alla, R.K.; Doudna, J.A. Enhanced Homology-Directed Human Genome Engineering by Controlled Timing of CRISPR/Cas9 Delivery. eLife 2014, 3. [CrossRef]

31. Liu, S.; Opiyo, S.O.; Manthey, K.; Glanzer, J.G.; Ashley, A.K.; Amerin, C.; Troksa, K.; Shrivastav, M.; Nickoloff, J.A.; Oakley, G.G. Distinct Roles for DNA-PK, ATM and ATR in RPA Phosphorylation and Checkpoint Activation in Response to Replication Stress. Nucleic Acids Res. 2012, 40, 10780-10794. [CrossRef] [PubMed]

32. Kanu, N.; Grönroos, E.; Martinez, P.; Burrell, R.A.; Goh, X.Y.; Bartkova, J.; Maya-Mendoza, A.; Mistrík, M.; Rowan, A.J.; Patel, H.; et al. SETD2 Loss-of-Function Promotes Renal Cancer Branched Evolution through Replication Stress and Impaired DNA Repair. Oncogene 2015, 34, 5699-5708. [CrossRef]

33. Bartkova, J.; Hořejší, Z.; Koed, K.; Krämer, A.; Tort, F.; Zieger, K.; Guldberg, P.; Sehested, M.; Nesland, J.M.; Lukas, C.; et al. DNA Damage Response as a Candidate Anti-Cancer Barrier in Early Human Tumorigenesis. Nature 2005, 434, 864-870. [CrossRef] [PubMed]

34. Vargas-Rondón, N.; Villegas, V.; Rondón-Lagos, M. The Role of Chromosomal Instability in Cancer and Therapeutic Responses. Cancers 2017, 10, 4. [CrossRef] 
35. Paull, T.T.; Rogakou, E.P.; Yamazaki, V.; Kirchgessner, C.U.; Gellert, M.; Bonner, W.M. A Critical Role for Histone H2AX in Recruitment of Repair Factors to Nuclear Foci after DNA Damage. Curr. Biol. 2000, 10, 886-895. [CrossRef]

36. An, J.; Huang, Y.-C.; Xu, Q.-Z.; Zhou, L.-J.; Shang, Z.-F.; Huang, B.; Wang, Y.; Liu, X.-D.; Wu, D.-C.; Zhou, P.-K. DNA-PKcs Plays a Dominant Role in the Regulation of H2AX Phosphorylation in Response to DNA Damage and Cell Cycle Progression. BMC Mol. Biol. 2010, 11, 18. [CrossRef]

37. Zeng, S.; Shen, W.; Liu, L. Senescence and Cancer. Cancer Transl. Med. 2018, 4, 70. [CrossRef]

38. González-Gualda, E.; Baker, A.G.; Fruk, L.; Muñoz-Espín, D. A Guide to Assessing Cellular Senescence in vitro and in vivo. FEBS J. 2021, 288, 56-80. [CrossRef]

39. Brinkmann, K.; Schell, M.; Hoppe, T.; Kashkar, H. Regulation of the DNA Damage Response by Ubiquitin Conjugation. Front. Genet. 2015, 6. [CrossRef] [PubMed]

40. Krum, S.A.; de la Dalugdugan, E.R.; Miranda-Carboni, G.A.; Lane, T.F. BRCA1 Forms a Functional Complex with $\gamma$-H2AX as a Late Response to Genotoxic Stress. J. Nucleic Acids 2010, 2010, 1-9. [CrossRef]

41. Ramadan, K.; Meerang, M. Degradation-Linked Ubiquitin Signal and Proteasome Are Integral Components of DNA Double Strand Break Repair: New Perspectives for Anti-Cancer Therapy. FEBS Lett. 2011, 585, 2868-2875. [CrossRef]

42. Stone, H.R.; Morris, J.R. DNA Damage Emergency: Cellular Garbage Disposal to the Rescue? Oncogene 2014, 33, 805-813. [CrossRef]

43. Vissers, J.H.; Nicassio, F.; van Lohuizen, M.; Di Fiore, P.; Citterio, E. The Many Faces of Ubiquitinated Histone H2A: Insights from the DUBs. Cell Div. 2008, 3, 8. [CrossRef]

44. Ran, F.A.; Hsu, P.D.; Wright, J.; Agarwala, V.; Scott, D.A.; Zhang, F. Genome Engineering Using the CRISPR-Cas9 System. Nat. Protoc. 2013, 8, 2281-2308. [CrossRef]

45. Oceguera-Yanez, F. Engineering the AAVS1 Locus for Consistent and Scalable Transgene Expression in Human IPSCs and Their Differentiated Derivatives. Methods 2016, 15, 43-55. [CrossRef]

46. Vichai, V.; Kirtikara, K. Sulforhodamine B Colorimetric Assay for Cytotoxicity Screening. Nat. Protoc. 2006, 1, 1112-1116. [CrossRef] [PubMed]

47. Rödiger, S.; Schierack, P.; Böhm, A.; Nitschke, J.; Berger, I.; Frömmel, U.; Schmidt, C.; Ruhland, M.; Schimke, I.; Roggenbuck, D.; et al. A Highly Versatile Microscope Imaging Technology Platform for the Multiplex Real-Time Detection of Biomolecules and Autoimmune Antibodies. In Molecular Diagnostics; Advances in Biochemical Engineering/Biotechnology; Seitz, H., Schumacher, S., Eds.; Springer: Berlin/Heidelberg, Germany, 2012; Volume 133, pp. 35-74, ISBN 978-3-642-37690-0.

48. Willitzki, A.; Lorenz, S.; Hiemann, R.; Guttek, K.; Goihl, A.; Hartig, R.; Conrad, K.; Feist, E.; Sack, U.; Schierack, P.; et al. Fully Automated Analysis of Chemically Induced $\mathrm{H} 2 \mathrm{AX}$ Foci in Human Peripheral Blood Mononuclear Cells by Indirect Immunofluorescence: Fully Automated ГH2AX Foci Analysis in PBMCs. Cytometry A 2013, 83, 1017-1026. [CrossRef]

49. Schneider, J.; Weiss, R.; Ruhe, M.; Jung, T.; Roggenbuck, D.; Stohwasser, R.; Schierack, P.; Rödiger, S. Open Source Bioimage Informatics Tools for the Analysis of DNA Damage and Associated Biomarkers. J. Lab. Precis. Med. 2019, 4, 1-27. [CrossRef]

50. Ni, D.; Xu, P.; Gallagher, S. Immunoblotting and Immunodetection. Curr. Protoc. Cell Biol. 2008, 83, 10-18. [CrossRef]

51. R: The R Project for Statistical Computing. Available online: https: / / www.r-project.org/ (accessed on 3 June 2020).

52. Ritz, C.; Baty, F.; Streibig, J.C.; Gerhard, D. Dose-Response Analysis Using R. PLoS ONE 2015, 10, e0146021. [CrossRef] 